\title{
As faces do (eco)turismo e o planejamento ambiental nas Unidades de Conservação do Brasil
}

\section{A the sides of (eco)tourism and environmental planning in Brazil Conservation Units}

\author{
CAVALCANTE ${ }^{1}$, M. B.; FURTADO ${ }^{2}$, E. M.; $\operatorname{SILVA}^{3}$, G. R.; MENESES ${ }^{4}$, L. F.
}

marcio-balbino@hotmail.com

\begin{abstract}
Resumo
Nas últimas décadas, a visitação em Unidades de Conservação, que engloba tanto o turismo quanto a recreação local, tem sido difundida como uma atividade capaz de conciliar conservação e uso sustentável da biodiversidade e geodiversidade, ao mesmo tempo em que pode gerar alternativas econômicas para as populações locais, além do apoio público para a sua proteção. Diante do exposto, o presente trabalho tem como objetivo analisar a prática do turismo em Unidades de Conservação no Brasil, bem como discutir a necessidade do planejamento territorial e ambiental no âmbito destas atividades turísticas desenvolvidas nestes espaços protegidos. Em presença dos resultados, considera-se fundamental a implementação de um planejamento territorial, pautada em ferramentas metodológicas e instrumentos de gestão que procurem conciliar conservação ambiental e uso turístico, levando em consideração os anseios das comunidades locais que residem no entorno das áreas protegidas.
\end{abstract}

Palavras-chave: Áreas Protegidas; Meio Ambiente; Gestão Territorial; Uso Turístico.

\begin{abstract}
In the last decades the visitation in Conservation Units, which encompasses both tourism and the local recreation, has been widespread as an activity capable of reconciling conservation and sustainable use of biodiversity and geodiversity, meanwhile it can generate economic alternatives for local populations and public support for their protection. Given the above, this study aims to analyze the practice of tourism in Conservation Units of Brazil, and to discuss the need for territorial and environmental planning in the context of these tourist activities in these protected areas. In the presence of the results, it is fundamental to implement a territorial planning, based on methodological and management tools that seek to reconcile environmental conservation and tourist use, taking into account the wishes of the local communities living around the Conservation Units.
\end{abstract}

Keywords: Protected Areas; Environment; Territorial Management; Tourist use.

\section{INTRODUÇÃO}

Nas últimas décadas, a criação de Áreas Naturais Protegidas é um dos principais instrumentos para a conservação da biodiversidade e geodiversidade mundial. Tal fato pode ser explicado, por um lado, pela degradação ambiental crescente, especialmente devido aos impactos da expansão urbano-industrial e pela devastação das florestas e, por outro, é que neste período a qualidade do ambiente começa a constituir elemento de destaque do produto turístico, de modo que a natureza e seus componentes tornam-se pretextos para a prática turística.

É nesse contexto que surgiram as modalidades de turismo definidas como alternativas ao de massa, a exemplo do turismo de natureza, que segundo Teles (2011) engloba o ecoturismo, turismo

\footnotetext{
${ }^{1}$ Márcio Balbino Cavalcante, DG/Grupo de Pesquisa TERRA, Universidade Estadual da Paraíba, Guarabira-PB, Brasil. 
de aventura, turismo educacional e uma profusão de outros tipos de experiências proporcionadas pelo turismo ao ar livre.

Dessa maneira, foi sendo construída uma forma de turismo em que a conservação da natureza estivesse aliada ao respeito aos atributos e às tradições dos núcleos receptores, considerando as suas leis, práticas e costumes, ao mesmo tempo em que promovesse educação ambiental e benefícios econômicos para as populações envolvidas (CAVALCANTE, 2012).

Nesse sentido, a visitação em Áreas Naturais Protegidas, que engloba tanto o turismo quanto a recreação local, tem sido defendida como uma atividade capaz de conciliar conservação e uso sustentável da biodiversidade e da geodiversidade, ao mesmo tempo em que pode gerar alternativas econômicas para as populações locais.

Diante do exposto, o presente trabalho tem como objetivo analisar a prática do turismo em Unidades de Conservação (UC's) no Brasil, bem como refletir sobre o planejamento territorial e ambiental destes espaços protegidos. E por último, sugerir instrumentos de gestão que procurem conciliar conservação ambiental e uso turístico.

\section{METODOLOGIA}

Para a fundamentação do estudo, utilizou-se da pesquisa e revisão bibliografia teórico-conceitual e trabalhos práticos acerca da temática supracitada, a saber: Geografia, Meio Ambiente, Unidades de Conservação, Turismo e Legislação Ambiental.

\section{REFERENCIAL TEÓRICO}

\subsection{A DIMENSÃO DO (ECO)TURISMO E A QUESTÃO AMBIENTAL}

Após a década de 1960, a emergência das questões ambientais, acompanhada de um processo crescente de valorização da natureza e proteção dos recursos naturais, foi sendo empreendida como uma forma de reaproximação entre homem e natureza, e, principalmente, pela tomada de consciência em relação aos desajustes gerados pelo atual paradigma econômico de desenvolvimento capitalista instalada à época.

Rodrigues (2001) afirma que esse movimento de valorização do ambiente é decorrente da difusão do pensamento ambientalista que, aliado à degradação das condições de vida, nas grandes cidades (poluição, violência, stress), vem estimulando um retorno e uma revalorização da natureza e das tradições locais por parte das populações urbanas. 
É nesse contexto que Chinaglia (2007, p. 51) ressalta que "um dos meios pelo qual o homem tem se reaproximado da natureza é por intermédio do ecoturismo". Esta é uma área que se configura como uma tipologia de turismo que vem crescendo mundialmente a cada ano, tendo como principal característica a utilização do patrimônio natural de forma sustentável, buscando sua proteção por meio da sensibilização e da educação ambiental.

Etimologicamente, o termo "eco" deriva do prefixo grego oikos, que significa lar ou habitat. Assim sendo, em uma primeira instância, ecoturismo significaria um deslocamento de pessoas interessadas em conhecer o nosso planeta, nossa casa e seus habitats (WEARING; NEIL, 2014, p. 27).

Nesse cenário, torna-se necessário, inicialmente, diferenciar o ecoturismo do turismo de natureza, geralmente utilizados como "sinônimos". Apesar de os dois conceitos serem utilizados indiscriminadamente, é importante que se explique que o primeiro está contido no segundo. Em outras palavras, o turismo de natureza compreende todas as modalidades de turismo realizadas no ambiente natural, como o ecoturismo, o turismo de aventura, o turismo de caça e pesca (WEARING; NEIL, 2014).

Na visão de Pires (2002) apud Cavalcante (2012), existe uma compilação de definições de ecoturismo. Tal fato é resultado do ponto de vista dos diferentes setores da sociedade envolvidos nessa atividade, a exemplo do "trade" turístico, dos organismos oficiais, das Organizações Não Governamentais (ONG's), das populações residentes, do turista e do meio acadêmico. Cada um desses setores tende a conceber a sua própria ideia de ecoturismo.

No Brasil, quando os órgãos de defesa do meio ambiente iniciam políticas integradas com os órgãos de turismo, através das “Diretrizes para uma Política Nacional de Ecoturismo”, em 1994, surgem ideias de conservação ambiental e sustentabilidade social na definição de ecoturismo:

Um segmento da atividade turística que utiliza de forma sustentável o patrimônio natural e cultural, incentiva sua conservação e busca a formação de uma consciência ambientalista através da interpretação do ambiente, promovendo o bem-estar das populações envolvidas (BRASIL, 1994, p. 19).

Encontram-se além dessa definição de caráter oficial, outras definições que destacam as premissas nas quais se fundamentam essa prática turística. Essas diferenciações de conceitos resultam da contradição entre o pensamento científico e as práticas ecoturísticas desenvolvidas no mercado econômico que normalmente não leva em consideração se a atividade desenvolvida condiz com a definição científica.

Em uma perspectiva econômica, Lindberg e Huber (2002) afirmam que o ecoturismo é visto como sinônimo de desenvolvimento socioeconômico; para eles, uma das principais vantagens deste 
setor é a de proporcionar um impulso que favorece tanto à expansão da conservação quanto o desenvolvimento econômico. Nessa perspectiva, o ecoturismo pode gerar oportunidades de emprego em regiões remotas e acredita-se que o ecoturismo exige menos investimentos do setor público em infraestrutura.

Segundo Rodrigues (2001, p.31) o ecoturismo é definido como sendo uma atividade econômica, de baixo impacto ambiental, que se orienta para áreas de significativo valor natural e cultural, e que através das atividades recreacionais e educativas contribui para a conservação da biodiversidade e da sociodiversidade, resultando em benefícios para as comunidades receptoras.

Com a evolução do conceito de ecoturismo, observa-se a necessidade da inserção de outras práticas, premissas e princípios, cuja característica principal é a preocupação com a preservação ambiental e a promoção de melhoria da qualidade de vida das populações locais (BASSO, 2007).

Nesse contexto, os princípios do ecoturismo devem assentar na promoção de suporte à conservação e proteção ambiental, por meio da potencialização da responsabilidade operacional com a utilização sustentada dos recursos (gerar parcerias com agentes locais e ONG's; em desenvolver atividades de baixo impacto ambiental, monitorar constantemente as atividades praticadas; proporcionar educação ambiental, entre outros); caso não cumpram esses princípios, a atividade turística não estaria concentrada na ótica do desenvolvimento sustentável (MOLINA, 2001).

Diante do exposto, pensar nos pilares do desenvolvimento sustentável significa defender um novo estilo de desenvolvimento que seja ambientalmente sustentável no acesso e manejo dos recursos naturais e na preservação da bio e geodiversidade; socialmente sustentável na redução da pobreza e das desigualdades sociais; politicamente sustentável ao aprofundar a democracia e garantir o acesso e a participação de todos nas decisões de ordem pública.

No Brasil, existem diversos cientistas contrários ao discurso do desenvolvimento sustentável, bem como a exacerbação da ideia de um turismo que seja sustentável. Para Rodrigues (2003), a sustentabilidade não está dada simplesmente com a elaboração de documentos, de modo que precisamos construí-la socialmente, envolvendo todas as atividades econômicas.

Para a autora, "a atividade turística é, em sua própria essência, incompatível com uma ideia de desenvolvimento sustentável", pois se encontra profundamente dependente da lógica e das normas do mercado.

[...] considerar a atividade turística como sustentável ou como integrante da possibilidade do desenvolvimento sustentável é apenas desviar os termos da questão sem analisar a complexidade de uma atividade econômica que tem por base o consumo de paisagens naturais exóticas ou a história passada (RODRIGUES, 2003, p. 174). 
Portanto, a autora é contra a ideia de turismo sustentável, por considerar que o turismo é um setor motivador da transformação da natureza e da paisagem em mercadoria. De fato, observa-se na prática um desafio para os empreendimentos vincularem lucratividade com a ideia de uma atividade “ecologicamente correta". Nesse sentido, a execução efetiva do ecoturismo muitas vezes não corresponde à sua definição teórica, causando a impressão para a sociedade, e até para alguns turistas, de seu conceito ser uma falácia.

Beni (2007, p. 470) na tentativa de resolver essa questão, afirma que no Brasil o ecoturismo está até o momento circunscrito a poucos casos, levando em conta que as nossas áreas de conservação e proteção ambiental não dispõem de uma política integrada e de um planejamento estratégico de uso e ocupação voltados especificamente para o turismo. Diante desse contexto, a realidade, levada a senso comum, quase que de forma invisível por sua sutileza, parece transformar o entendimento do ecoturismo num conjunto de atividades preocupado com a conservação e a educação ambiental, mas, não necessariamente, ecologicamente correto em toda a sua complexidade operacional.

\section{2. (ECO)TURISMO E PLANEJAMENTO AMBIENTAL NAS UNIDADES DE CONSERVAÇÃOO}

A criação das Áreas Protegidas no mundo, e definidas no Brasil como Unidades de Conservação (UC's), tem-se configurado em uma das principais formas de intervenção do Estado na proteção de consideráveis e representativas áreas territoriais dos biomas, frente ao acelerado processo de apropriação e exploração do meio ambiente, imposto pelo sistema capitalista. Paradoxalmente, tem sido esse mesmo Estado que vem agindo de modo a fomentar a expansão desse sistema (CAVALCANTE, 2012).

Segundo o Sistema Nacional de Unidades de Conservação (SNUC), instituído pela Lei n 9. 985, de 18 de julho de 2000, entende-se por Unidades de Conservação:

\footnotetext{
Espaços territoriais e seus componentes, incluindo as águas jurisdicionais, com características naturais relevantes, de domínio público ou privado, legalmente instituídos pelo Poder Público, com objetivos de conservação e de limites definidos, sob-regime especial de administração, às quais se aplicam garantias adequadas de proteção (BRASIL, 2000).
}

O SNUC inclui todas as UC's brasileiras, nos âmbitos federal, estadual e municipal. Compete ao SNUC estabelecer os critérios e as normas para a criação, implantação e gestão das Unidades de Conservação, cujos objetivos principais dessa Lei estão descritos nos seus artigos 3 e 4: 
- Proteger as espécies ameaçadas de extinção no âmbito regional e nacional, contribuir para a preservação e a restauração da diversidade de ecossistemas naturais;

- Proteger paisagens naturais pouco alteradas de notável beleza cênica;

- Proteger as características relevantes de natureza geológica, geomorfológica, espeleológica, arqueológica, paleontológica e cultural;

- Proporcionar meios e incentivos para atividades de pesquisa científica, estudos e monitoramento ambiental;

- Favorecer condições e promover a educação e interpretação ambiental, a recreação em contato com a natureza e com o turismo ecológico (BRASIL, 2000).

Através do SNUC foram criados duas grandes categorias de manejo, as Unidades de Proteção Integral, com o objetivo básico de preservar a natureza, admitindo-se apenas o uso indireto dos recursos naturais e as Unidades de Uso Sustentável, de forma a compatibilizar a conservação da natureza com o uso sustentável dos recursos naturais.

As Unidades de Proteção Integral são compostas pelas categorias de unidades de conservação denominadas de Estação Ecológica, Reserva Biológica, Parque Nacional, Monumento Natural e Refúgio de Vida Silvestre. Enquanto as Unidades de Uso Sustentável são compostas pelas categorias de unidades de conservação denominadas de Área de Proteção Ambiental, Área de Relevante Interesse Ecológico, Floresta Nacional, Reserva Extrativista, Reserva de Fauna, Reserva de Desenvolvimento Sustentável e Reserva Particular do Patrimônio Natural. Cada categoria das UC's criadas com a implementação do SNUC possui seus objetivos e características específicas, determinados especialmente pela forma de proteção e usos permitidos (BRASIL, 2000).

O SNUC considera a importância da gestão participativa. Cada UC deve possuir seu conselho gestor, o qual deve ser constituído por representantes de órgãos públicos, organizações da sociedade civil, da população local, entre outros atores que estejam envolvidos de alguma forma com a Unidade (BRASIL, 2000).

Para Matos de Souza et al. (2011), o SNUC contribuiu para os avanços na política de expansão e gestão da área protegida por unidades de conservação nas três esferas de governo (federal, estadual e municipal) e oferece uma visão integrada do conjunto de unidades de conservação no território brasileiro. A relação entre o Estado, os cidadãos e o meio ambiente ganha força com a criação de mecanismos que ampliam a participação da sociedade na gestão do Sistema.

Vale destacar, contudo, que muitas UC's importantes para o país foram implementadas antes da criação do SNUC, entre eles, os primeiros Parques Nacionais, que se deram em 1937 - Itatiaia, e em 1939 - Iguaçu e Serra dos Órgãos.

No Brasil, as UC's, principalmente os parques nacionais e estaduais, estão entre as principais destinações turísticas. Tanto é que o SNUC contempla a prática de atividades turísticas, no caso, o ecoturismo (CAVALCANTE, 2012). Desta forma, os parques exercem de fato uma atração muito 
forte por aqueles que desejam usufruir a beleza da fauna e da flora no seu habitat natural, podendo o desenvolvimento da atividade ecoturística servir de aporte para a interação do homem com a natureza. Contudo, esta é uma questão que gera muitos conflitos - conservação versus uso do espaço - diante da função e do propósito das UC's, bem como, conflitos relacionados com a efetividade dos princípios e benefícios e dos impactos potencialmente gerados pelo ecoturismo.

Entre as Unidades de Conservação paraibanas, merece destaque o Parque Estadual da Pedra da Boca (PEPB), localizado no município de Araruna, instituído pelo Decreto Estadual n ${ }^{\circ} 20.889$, em 07 de fevereiro de 2000 (Paraíba, 2000). A criação do PEPB foi criada com o objetivo de preservar o ambiente natural e impulsionar o turismo local. A principal característica do Parque são suas formas de relevo, bastante diferenciadas das demais áreas da região.

Dessa forma, a institucionalização do PEPB, constituída de 157,3 hectares de extensão territorial, foi em virtude de preservar seu conjunto rochoso de grande beleza cênica, de composição granítica porfirítica, cujas configurações geológico-geomorfológicas são ímpares, e também por abrigar espécies da flora e da fauna endêmicas e representativas do bioma caatinga. Em seu ambiente são desenvolvidas as atividades turísticas, como o turismo ecológico, turismo de aventura, turismo religioso e o turismo educacional (CAVALCANTE, 2012).

Anteriormente a sua instituição como Parque Estadual, vinha se registrando na região a prática de atividades ligadas ao turismo de aventura, como a escalada e rapel no local, bem como atividades educacionais e científicas. A partir de 1990, com o desenvolvimento espontâneo do turismo sem ordenamento, bem como o interesse por parte do governo do estado da Paraíba, veio a definir a vocação turística da área.

Diante desse contexto, o ecoturismo no PEPB é realizado através dos passeios na área do parque, caracterizados por caminhadas guiadas ou autoguiadas nas diversas trilhas catalogadas na área territorial da unidade, como as trilhas da Aventura, da Boca, das Cavernas, da Caveira, da Pedra do Letreiro, do Gemedouro.

O turismo de aventura é outra modalidade turística que promove a prática de atividades de aventura e esporte recreacional no PEPB. Essas atividades são realizadas em ambientes naturais, envolvem emoções e riscos e exigem o uso de técnicas e de equipamentos específicos, bem como a adoção de determinados procedimentos de segurança pessoal (CAVALCANTE, 2012).

No que se refere à infraestrutura, o Parque conta com uma estrutura mínima, apenas com uma guarita na entrada principal e uma antiga casa de ex-morador, que servem de apoio às atividades desenvolvidas na área.

Com relação aos recursos humanos, o PEPB conta apenas com um gerente, que exerce o trabalho voluntário, e, atualmente, não existe guarda-parques que possam colaborar na manutenção de uma 
área geográfica de 157,27 ha., além de cerca de 6.000 turistas ao ano que visitam o local. A evidente sobrecarga de funções para apenas um indivíduo gera limitações quanto à fiscalização e apoio efetivos aos turistas e visitantes na área.

Dessa maneira, a falta de infraestrutura para visitação no PEPB dificulta o desenvolvimento de uma atividade turística mais harmoniosa com a natureza, pois as importantes ações educativas e de sensibilização normalmente são promovidas apenas pelos gestores da unidade, e a "maioria das pessoas que procuram essas áreas têm pouca noção do que seja uma unidade de conservação, do que significa conservação da natureza e qual o papel do ser humano na natureza" (KINKER, 2005, p.76).

Segundo dados da entrevista com o gestor, outro ponto negativo que dificulta a gestão do PEPB é a inexistência do seu Plano de Manejo; esse Plano é fundamental para que a UC possa atender aos seus objetivos de manejo, uma vez que define um conjunto de ações interligadas e coerentes para um melhor direcionamento das ações de intervenção na mesma (BRASIL, 2000).

O Parque completou, em 2016, 16 anos de sua criação sem esse instrumento normativo. Segundo o SNUC, deve ser elaborado até 5 anos após a instituição de uma UC. A fim de não prejudicar os objetivos de conservação da natureza dos Parques Estaduais, em tese, estes só poderiam estar abertos à visitação a partir da elaboração de seu Plano de Manejo.

Desse modo, é fundamental a elaboração urgente desse documento para o PEPB, uma vez que as normas de conduta e critérios do uso indireto dos recursos naturais devem ser estabelecidas. Convém ressaltar que a existência das formações rochosas e espécies endêmicas da caatinga contidas no parque deveriam garantir a imediata realização do seu plano de manejo.

Para a consolidação do planejamento e administração das UC's, Vallejo (2005, p. 28) afirma que a "forma de organização institucional dos governos é fundamental". Desse modo, o autor acrescenta:

A administração de muitas UC's envolve diversos setores institucionais de forma direta e indireta (meio ambiente, turismo, agricultura, mineração, urbanismo, etc) e a adequada comunicação interinstitucional é condição essencial. Além disso, deve-se considerar a organização intrainstitucional para se evitar, por exemplo, a excessiva centralização das agências gestoras das unidades.

Assim, embora evidenciados avanços na gestão das UC's brasileiras, ainda é necessário fortalecer a participação social nesse processo, de forma que a população local e setores envolvidos compreendam os serviços e benefícios ambientais, sociais e econômicos potenciais destas unidades e contribuam para aperfeiçoá-los. 
É certo que se esses espaços são geridos de forma realmente participativa, os conselhos gestores tendem a colaborar com a resolução dos conflitos e com a própria eficácia das unidades de conservação dentro dos objetivos para os quais foram criadas.

\section{CONSIDERAÇÕES FINAIS}

A visitação nestas áreas territoriais, como qualquer outra atuação humana no espaço geográfico, comporta alguns efeitos que são intrínsecos ao desenvolvimento da atividade. Como o impacto nulo é praticamente impossível de ser alcançado, o que se deve buscar é a minimização dos impactos negativos da visitação e a maximização dos impactos positivos, valorizando as populações locais e qualidade da experiência do visitante.

Sendo assim, a busca por um desenvolvimento em bases sustentáveis e equitativas para a sociedade como um todo requer a consolidação de políticas públicas compatíveis com as realidades ambientais locais, que exerçam influência direta no contexto econômico e socioambiental. Para isso é necessário maior investimento e visão estratégica para que as UC's possam, além de conservar os ecossistemas e a bio e geodiversidade, de fato gerar renda, emprego, desenvolvimento e propiciar uma efetiva melhora na qualidade de vida das populações locais e das regiões onde se inserem.

Diante do exposto, a conexão entre as UC's e os outros setores e atividades econômicas locais, regionais e nacionais deve ser claramente percebida e internalizada no âmbito das práticas de uso destes ambientes.

Considera-se, desta forma, fundamental a implementação de um planejamento territorial pautado em ferramentas metodológicas e instrumentos de gestão que procurem conciliar conservação ambiental e uso turístico, levando em consideração os anseios das comunidades locais que residem no entorno dos espaços protegidos, a saber: Plano de Manejo; zoneamento ambiental; criação de Conselho Consultivo; estudo de capacidade de carga; formação de guias e guarda-parques; promoção de projetos e ações de educação e interpretação ambiental.

\section{REFERÊNCIAS}

BASSO, K. G. Furlan. Políticas públicas do turismo em áreas naturais e a evolução do conceito de ecoturismo no Brasil. In CONGRESSO NACIONAL DE ECOTURISMO, 2007. Anais ... 2007. Disponível em: www.physis.org.br/ecouc/artigos. Acesso em: 20/09/2016.

BENI, Mario Carlos. Análise Estrutural do Turismo. 8. ed. São Paulo: Senac, 2007.

BRASIL. Diretrizes para uma Política Nacional de Ecoturismo. Brasília: EMBRATUR, 1994.

BRASIL. Lei no 9.985, de 18 de julho de 2000. Sistema Nacional de Unidades de Conservação - SNUC. Brasília: PLANALTO, 2000. Disponível em: 
http://www.planalto.gov.br/civil_03/LEIS/L9985.htm. Acesso em: 30/06/2016.

CAlvalcante, M. B. Parque Estadual Pedra da Boca (Araruna/PB): uma avaliação sobre as atividades turísticas e as ações de gestão territorial. Dissertação de Mestrado apresentada ao Programa de Pós-Graduação e Pesquisa em Geografia da Universidade Federal do Rio Grande do Norte. Natal, 2012, 146 p.

CHINAGLIA, C. R. Desenvolvimento Sustentável, Participação e Ecoturismo. In CASTELLANO, E. G.; FIGUEIREDO, R. A. de; CARVALHO, C. L. de. (Eco) Turismo e Educação Ambiental: diálogo e prática interdisciplinar. São Paulo: RiMa, 2007.

KINKER, S. Ecoturismo e conservação da natureza em parques nacionais. 2. ed. Campinas: Papirus, 2005 .

LINDBERG, K.; HAWKINGS, D. Ecoturismo - um guia para planejamento e gestão. 4. ed. São Paulo: SENAC, 2002.

MATOS SOUZA et al. Dez anos de história: avanços e desafios do Sistema Nacional de Unidades de Conservação da Natureza. In MINISTÉRIO DO MEIO AMBIENTE - MMA. Dez anos do Sistema Nacional de Unidades de Conservação da Natureza: lições do passado, realizações presentes e perspectivas para o futuro. Brasília: MMA, 2011.

MOLINA, S. Turismo e ecologia. Bauru: EDUSC, 2001.

PARAIBA. Decreto n. ${ }^{\circ} 20.889$, de 07 de fevereiro de 2000. Cria o Parque Estadual da Pedra da Boca, e dá outras providências. Disponível em: http://www.sudema.pb.gov.br/legis_files/decreto20889.html . Acesso em: 10/08/2015.

RODRIGUES, A. B. (Org.). Turismo e espaço: rumo a um conhecimento transdisciplinar. São Paulo: Hucitec, 2001.

RODRIGUES, A. M. Desenvolvimento sustentável e atividade turística. In SERRANO, C.; BRUHNS, H. T.; LUCHIARI, M. T. D. P. (Orgs.). Olhares contemporâneos sobre o turismo. Campinas: Papirus, 2003.

TELES, R. Turismo e meio ambiente ou turismo da natureza? Alguns apontamentos para organização dessa modalidade. In TELES, R. (Org.). Turismo e meio ambiente. Rio de Janeiro: Elsevier, 2011, p. 03 - 20.

VALlejO, L. R. Políticas Públicas e Conservação Ambiental: territorialidades em conflito nos Parques Estaduais da Ilha Grande, da Serra da Tiririca e do Desengano (RJ). Tese de Doutorado em Geografia apresentado ao Instituto de Geociências, Universidade Federal Fluminense, Niterói, 2005. 342 p.

WEARING, S.; NEIL, J. Ecoturismo: impactos, potencialidades e possibilidades. 2. ed. São Paulo: Manole, 2014.

Recebido em: 14/08/2016

Aceito para publicação em: 01/10/2016 